\title{
Chapter Five:
}

\section{Time, motion, rhythm: reality, perception and quantification}

In this chapter I look at discussions of the fundamental nature, both of time itself and of its perception and measurability. Here again medical writing, that of Galen especially, draws upon existing philosophical debates. It introduces perspectives which enrich those debates themselves, while also shedding light on ancient approaches to the challenges of the measurement of time in relation to motion - of the assessment of speed, frequency and rhythm. The value of a study of Galen's - and other medical, as well as musical - discussions, then, is not just that they engage with and contribute in interesting and unexpected ways to the philosophical debate. Such discussions also make clear the relevance of the abstract conceptions in real-life contexts - for example in clinical contexts, as well as in relation to the practical challenges of the assessment of time, speed or rhythm. We shall begin with the more abstract, theoretical analyses, before moving to a consideration of some of these practical significances, in both musical and medical contexts.

Most of Galen's discussions in this area, indeed, consider related questions conjointly - the nature of time, the relationship of time to space and motion, the nature of our perception of these - and arise in the context of enquiries related to clinical practice, specifically that concerning the accurate discernment or measurement of the motions of the pulse. There is also a series of remarks of a more theoretical nature, which are available to us in the form of 'fragments' - that is to say, as statements attributed to Galen, either as verbatim quotations or in indirect form, by later authors, unfortunately shorn of their original argumentative context. We shall proceed by considering first this more theoretical - and harder to interpret - material before moving to the discussions in the treatises on the pulse, which we shall consider alongside evidence for the related theories of the earlier pulse theorist Herophilus of Chalcedon. There, we shall be considering the principles and processes involved in the measurement of very small time units, and also of ratios between time units, as reflected in ancient medical evidence of attempts to measure speed or rhythm. Throughout, the question arises of the relative or absolute basis of the measurements, and of the extent - or limits - of any attempts at quantification.

First, let us give a very brief account of the relevant previous tradition of theoretical discussions of time. 


\section{Philosophical questions and the relationship of time to motion}

The Greek philosophical tradition centres on a number of core problems or paradoxes regarding time. Is time real? Is it continuous or atomic in its structure? Is time a kind of motion, and if not what is the relationship between the two? How is time related to eternity? Is the existence of time in some sense dependent on the human observer? How can we understand or define a moment of time, or the relationship of the present to the past and future? ${ }^{1}$

I offer here a highly simplified account of, as it were, the key moments in the history of this philosophical discourse.

Plato made a fundamental distinction between eternity (aiōn) and time (chronos), related to his distinction of the ideal or intellectual realm from the mutable, physical one of everyday observation and experience. Eternity involves no change; time is a feature of the world of coming-to-be (genesis) rather than that of true being, that is of the physical, perceptible world: it arises as a function of the creation of the cosmos, the heavenly bodies and their motions coming about as the instruments of its measurement. Relatedly, the perception or measurement of time, and perhaps even time itself, only exist in relation to a human observer. $^{2}$

This latter thought is taken further in the subsequent Platonic tradition, especially by Plotinus, for whom eternity and time can be seen as corresponding to two modes of existence, the former that of the Intellect, to which human beings strive to return, the latter played out in our ordinary, materially conditioned, lives. ${ }^{3}$ Time, for Plotinus, is 'the life of the soul in a movement that changes from one way of life to another' (Enneads 3.7.11.43-5). Central here is the notion of time as dependent on, or a feature of, human life - more specifically, of the

1 Still fundamental here is Sorabji (1983), following these and other philosophical topics concerned with time from classical Greek to mediaeval times.

2 In the Timaeus, time is created as an image of eternity, as a concomitant of the creation of the universe; the division into time units - and indeed that into past, present and future - are a function of the human observer and of physical motion and change (37d-38b). (Cf. the characterization of time as 'an image of eternity moving according to number', $\kappa \alpha \tau$ ' o’pı $\theta \mu$ ov ioṽ $\sigma \alpha v$

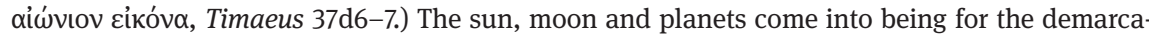
tion and monitoring of time (38c-39e). As we shall see, this gives rise to an interpretive question: is time in some sense a feature or function of physical motion - dependent upon it for its existence - or is rather simply that by which motion is measured?

3 Plotinus elaborates his views on time and eternity (also giving a substantial account of the previous tradition) in his Ennead 3.7; for further analysis see Beierwaltes (1967), Smith (1996), Tempest-Walters (2020). 
restless human soul feeling the need to depart from unity and eternity - rather than as something existing independently of us. Nevertheless, Plotinus is clear that time is not itself a motion but 'that within which physical motion takes place'. Here he is rejecting a view - and an interpretation of Plato - apparently widespread amongst Platonic commentators, according to which time is, indeed, a kind of motion - the motion of the 'whole', or of the 'sphere'. ${ }^{4}$ Aristotle too, as we shall see shortly, suggests that the view of time as a form of motion is that most widespread in his milieu.

The motivation for such a view is apparently that the revolutions of the heavenly bodies, or of the whole sphere, provide a constant against which time is measured. (For the fundamental 'two-sphere' view underlying ancient astronomical observations and theories see above, pp. 52-4 and figure 7.) Plotinus objects to this, pointing to the different speeds of motion of different heavenly bodies, and arguing that therefore time measurement requires a standard external to all such bodies. Time does not, then, consist in their motion; rather, those bodies have been generated in order to make time manifest and delimited, in order for there to be a visible measure (Enneads 3.7.8; 3.7.12). Plotinus also argues that time is that by which we quantify rather than being itself quantifiable (here taking issue with Aristotle: Physics 4.11, 219b7-8 and 4.12, 220b8).

Of course there is, in one sense, a kind of time (though it is not by Plotinus called 'time', chronos) that is not dependent on or intertwined with human experience, namely eternity (aiōn). Indeed, the relationship of time to eternity is, for Plotinus, closely parallel to the relationship of Soul, or of experience bound up inextricably with the physical cosmos, to that of the Intellect, the noetic realm of which that cosmos is a copy. ${ }^{5}$

4 The view is attributed to other commentators as an interpretation of Plato by Simplicius, On Aristotle's Physics 4.10, 700,16-22 Diels and 705,3-7 Diels. The view of the second-century Platonist Plutarch is that time is 'motion in an orderly fashion that involves measure and limits and revolutions' (Platonic Questions 8.4, 1007c-d).

5 I simplify here drastically. Whether, for Plato and his successors (and for Parmenides before him), eternity should be understood as a sort of time, namely time of endless duration - an infinity of time - or rather as timelessness, is problematic and debated; see Sorabji (1983): 98-130. What is clear, at least, for Plotinus and other Neoplatonists, is that the nature and the experience of time and of eternity are fundamentally different in nature, that the highest life for Plotinus involves a move away from the mode of existence entailed by time and (back) to that involved in eternity. The question arises, whether or not it is actually we who can have experience of the latter, which belongs to the 'higher' realm, above or beyond the individuation and physicality involved in human souls or selves. On the experiential aspect of Plotinus' account see Sorabji (1983): 157-63 and, in much more detail, Tempest-Walters (2020). 
We have followed a train of thought from Plato to the later Platonic tradition; let us now move back to Plato's immediate successor, Aristotle, and briefly consider his hugely influential discussion of time in the Physics. ${ }^{6}$ As already observed, Aristotle takes it that amongst his own contemporaries some view of time as a form of motion is the standard one. He states that time has been 'usually supposed to be motion and a kind of change'; and it seems likely that in the generations immediately following, the early Stoics, too, subscribed to some version of this 'universally supposed' account: the view is attributed to them that time is 'the interval of motion'.

Both the themes highlighted so far in our overview of philosophical views of time - the relationship with change or motion and the relationship with the human observer - are central to Aristotle's analysis. In summation of the former relationship, Aristotle argues that time is not itself a kind of motion or change, but is nevertheless inseparable from, or inconceivable without, change. It 'does not exist without change' (Physics 4.11, 218b21), or 'without motion and change' (218b33-219a1); 'time is not a motion, nor is it without motion' (219a1-2). The definitional formula settled upon is the following: 'time is a number of change with respect to the before and after' (219b1-2).

I draw attention to two points in particular. The first is the grounds for the insistence on the inseparability, or inextricability, of time and motion. One motivation seems to be that our awareness of time is inextricable from our awareness of change or motion: we can only discern the passing of time through some perception we have of change taking place within that time. Here, Aristotle talks of the 'motion in the mind' by which we know that time has elapsed. ${ }^{8}$ Secondly, in order for the above definition to be meaningful, 'before' and 'after' must be understood as taking their primary sense from something other than time. That is, if 'before' and 'after' are simply identical in meaning to 'earlier in time' and 'later in time', respectively, then the above definition comes out as: 'time is a number of change with respect to what is earlier in time and later in time' - which clearly involves a circularity. Aristotle does, indeed, distinguish different senses of 'before' and 'after' (which could also be translated 'prior' and 'posterior'), and his view seems to be that the primary conceptual applica-

6 For philosophical analysis of Aristotle's account see especially Coope (2005).

7 Aristotle, Physics 4.10, 218b9-b9-10; for the Stoics, SVF 1.93; 2.509; 2.510 and 2.515.

8 'We perceive motion and time simultaneously; for even if it is dark and we are undergoing no bodily experience, but there is some motion in our mind (psychē), we are immediately aware that some time has elapsed', Physics 4.11, 219a3-6. 
tion of the terms is to magnitude, from which follows that to place, and then that to time. ${ }^{9}$

Aristotle raises some different questions, too: for example, the relationship of time to number; the question, whether it is continuous or atomic in its structure, with the related problem of its theoretically infinite divisibility, as related to our perception of moments of time; the paradox of the 'ceasing instant', or of how it is that the present becomes the past, or how one is to conceptualize the boundary between them.

A large volume of scholarship has been devoted to the elucidation of the considerable intricacies of Aristotle's discussion, and to the question of its coherence or persuasiveness, and it is beyond my scope to engage with that scholarship in detail here. The above account of certain crucial points of Aristotle's analysis, and of the problems that they raise for the later tradition to grapple with, will suffice for the purposes of our further investigations, which will focus on the response given by Galen to this Aristotelian account; on Galen's own account of the relationship between time and motion, and between both and the human observer; and on the significance of these questions for the medical discourse.

Before turning to that response and that further discussion, however, it will be helpful to conclude our scene-setting with a brief summary of two further sets of time-related sources and discussions, namely those focussed on atomism or the atomic structure of time, on the one hand, and those concerned with the (in some ways closely related) analysis of time units and rhythms, in musical theory, on the other.

Aristotle favours the view that time, like the physical universe, is continuous in its structure, and he attributes to the proponents of atomic theory an atomism not just of matter, but also of time, taking the one kind of atomism to be entailed by the other. ${ }^{10}$ Beyond Aristotle's evidence, we also have testimony for the notion of atomic or indivisible units of time - again in conjunction with an analogous conception of matter - being espoused by Diodorus Cronus. ${ }^{11}$

9 Further on the structure of Aristotle's arguments on the priority of 'before and after' in motion, and space, to that in time, see Coope (2005: 47-81), identifying as a central motivation the claim to explain temporal asymmetry on the model of the parallel asymmetry, or ordered nature, of the other two. A vindication of Aristotle's views in general, and of the coherence of his account of this relationship in particular, is attempted by Detel (forthcoming).

10 See Physics 6.1, 231b18-20: 'It is logically the same thing for magnitude, time and motion to be composed of indivisibles, and to be divided into indivisibles or into nothing.'

11 The most relevant text is Sextus Empiricus, Against the Mathematicians 10.119-20, where the language used is that of the 'unparted' or 'partless' (amerēs) (though some scholars have doubt- 
A connection may be drawn between this analysis of time within the Atomist tradition and an account of rhythm which is found in a technical work of music theory. The fourth-century Aristotelian music theorist Aristoxenus of Tarentum developed a theory of rhythm based on a notion of 'rhythmizables' (rhuthmizomena), that is, domains that admit of temporal analysis or division, ${ }^{12}$ and here he proposed the notion of 'primary times' or 'primary time units' (prōtoi chronoi), that is, of minimal units of time which admit of no further division.

Both the further interpretation of this scheme and its relevance to the theoretical and practical discussions of time and speed measurement found in medical writing constitute complex questions, to which we shall return.

For the moment, let this brief summary suffice by way of pointing to the most relevant elements of the theoretical background, in both philosophical and musical discussions. We shall proceed to consider in more detail the views of Galen, of both a philosophical/theoretical nature and of a more practical and clinically-oriented nature; and in the latter context we shall contextualize his approach and his analysis in its relationship with the previous medical, and also musical, discourse.

\section{Galen on time (1): evidence for his theoretical analysis}

Let us then consider Galen's 'fragmentary' remarks on the nature of time, that is, those attributed to him by later authors, and apparently deriving from his lost work of logical theory and method, Demonstration. The texts in question are brief, and isolated from their original context; and they consist of a mixture of indirect attributions and verbatim quotations. They are relayed by hostile witnesses, the Aristotelian commentators Themistius and Simplicius, who offer a cursory reconstruction of the Galenic argument against Aristotle in order to refute it, and who are writing roughly two and four centuries after the time of Galen, respectively, as well as possibly introducing their own distortions and their own terminology. The text of Simplicius, moreover, is at least partially copied from the text of Themistius. From the point of view of the scholar trying to reconstruct an author's original argument or meaning, therefore, these texts

ed whether this language should be taken to imply an atomic view of time; on this issue see Sorabji 1983: 19-20). For a summary of the evidence for and scholarship on Diodorus, see Sedley (2009); and see further Sedley (1977); Denyer (1981), (2009).

12 On Aristoxenus see Barker (1978), (2005); Litchfield (1988); Pearson (1990), West (1992), Gibson (2005). On the relevance of Aristoxenus to the medical discourse, as further discussed below, see Berrey (2017). 
manifest some highly problematic features; they also await systematic analysis in the context of Galen's thought. ${ }^{13}$ Nevertheless, it seems that something of interest can be gleaned from them.

In the interests of clarity, I offer a brief summary of what I believe that something to be, before laying out the most relevant of these texts for closer inspection.

Galen parts company with Aristotle on the relationship of time and motion, and on the nature of our perception of them. As outlined above, Aristotle says that the perception of time is in some sense only possible because of motion, and that our understanding of before and after in time is dependent on the spatial notion of before and after. Galen apparently counter-argues that the perception of time is sui generis - that time can only be defined in its own terms and that it is not true that our perception of it is inextricable from that of motion. In this context, then, Galen also denies that the spatial concept of 'before and after' can be transferred to the assessment of time. He thus perhaps accuses Aristotle of precisely the circularity mentioned above. For if 'before' and 'after' have a specific meaning in relation to time, and their use in application to time can only be understood in relation to this specific meaning, and not on analogy with or by transfer from a spatial conception, then a definition of time in terms of 'the before and after' is simply a definition of time in terms of time. ${ }^{14}$

Here is the first testimony, which comes from Themistius' commentary on (and justification of the views expressed in) that central discussion in Aristotle's Physics.

One should pay no attention to Galen, who holds that time is defined through itself. For, having given a detailed enumeration of the many meanings of the before and after, he states that none is applicable to the definition [of time] except the one with respect to time, so that time is 'the number of motion with respect to time'. But it must be understood that the before and the after in motion are not respectively before and after because of time ... it comes about from that in relation to magnitude and position, with which it is continuous. Aristotle states this explicitly too: 'The before and after in place is primary; this is

13 Such analysis will be provided by Sean Coughlin, Matyáš Havrda and Pauline Koetschet, who are working on an edition of Galen's fragmentary Demonstration on the basis of all the testimonia. My remarks and summary analysis here are, by contrast, highly provisional. I am extremely grateful to Sean Coughlin for drawing my attention to these texts, and for personal communications related to them.

14 It could be argued, conversely, that he embraces this circularity, as it were on Aristotle's behalf, since his claim is indeed that time can only be understood in terms of time, that only the temporal sense of 'before' and 'after' is applicable to it. At any rate it seems he must argue that if one accepts Aristotle's definition of time, one must accept the circularity; he is attacking the move by which Aristotle transfers the spatial sense of 'before' and 'after' to the temporal one. 
where it is in position; but since it is also in magnitude, it is necessarily also in motion' [219a14-17]. Still, even if it be granted that the before and after in motion mean nothing other than the before and after in time, as he thinks, what problem arises from that? ${ }^{15}$

The second passage is taken from a little earlier in the same text.

Evidently, then, time is not without motion - but not in the manner of Galen's interpretation, that is, because it is when in motion that we conceive of time: that is what he takes Aristotle to be saying here. Rather, it is because the notion of time is inextricably linked to that of motion. Why, then, did Galen pointlessly contest this, and produce arguments against it, as follows? 'After all,' he says, 'we also have a conception of immovable things while ourselves being moved - such things as the poles, or the centre of the earth, and these things are not "with motion".' He should have paid attention to where Aristotle explicitly says 'for we perceive time and motion simultaneously'. It makes a very great difference whether we take it that time [has] something of motion on the grounds that [its conception] is inextricably linked to the conception of motion, or on the grounds that it is while in motion that we conceive of time. But this fellow is like this in many contexts. ${ }^{16}$

We move to the first of the passage from Simplicius.

On the basis of these statements the remarkable Galen, in the eighth book of his Demonstration, supposes that Aristotle is stating that time is not without motion on the following grounds, namely that it is when in motion ${ }^{17}$ that we conceive of it; here he introduces to the argument the supposed absurdity that completely unmoved bodies would have to be 'with motion', since our conception of them too is 'with motion', for we do not conceive of anything while our conception is devoid of motion. He might equally say on these grounds that unextended things could not be without extension, since we conceive of them with extension (acting for the most part through the imagination). ${ }^{18}$

Here, the interpretation is attributed to Galen that by 'time is not without motion' Aristotle means that we, the subjects or perceivers of time, are in motion at any point at which we conceive or conceptualize it; if there were no more to the argument than this, then, everything which we conceptualize would have to be conceptualized as involving motion, since we are ourselves never at rest.

A little further on Simplicius produces further anti-Galenic arguments, partially overlapping with those of the first passage from Themistius above, while also introducing some new material.

15 Themistius, On Aristotle's Physics, 4.11 (149,4-19 Schenkl).

16 Themistius, On Aristotle's Physics 4.11 (144,23-145,2 Schenkl).

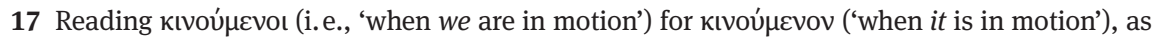
seems required by comparison with the summary of the same argument above in the Themistius text.

18 Simplicius, On Aristotle’s Physics 4.11 (708,27-34 Diels) 
Since the most learned Galen argued against some of these statements, saying that time is made evident through itself, let us present his argument for discussion. [There follows, almost verbatim, the second sentence of the first Themistius passage above, and then Themistius' counter-argument (with explicit attribution to him), from 'But it must be understood' to 'also in motion'.]

To this Galen might respond that the before and after in motion is consequent upon that in magnitude, for it is in this context that motion, in terms of before and after, is especially in relation to place: that is what it is to be before and after in magnitude. But that the before with respect to time, as already stated, is something else, which accompanies the motion in terms of before and after, but does not possess before and after in place, but in the extension of being, this being something distinct from that in terms of place, which comes about through motion.

Themistius introduces a second solution, too: [there follows the passage from the first Themistius passage above: 'Still, even if it be granted', etc. ...]

Galen might respond to this, too, as follows: that if the before and after in motion were the same thing as the before and after in time, then the statement that time was the before and after in motion would be sound, and in that case time would not be made evident through itself. If, however, that with respect to place is one thing, which is not temporal, while that with respect to time is another, then one would have to state that time is the before and after in motion with respect to time. Perhaps, then, one must understand the before and after in terms of the extension of being, not in terms of place, and so time is signified through itself. And its name, then, will not be, in straightforward terms, the same as 'the before and the after', but the same as a particular kind of before and after; and this is the definition. ${ }^{19}$

There is a certain amount here that is not clear, both in the counter-arguments to Aristotle attributed to Galen and in the refutations of these by Themistius and Simplicius. There is, too, one specific problem of interpretation, arising from a point in the text which otherwise might be thought to be the most helpful in elucidating Galen's position. We feel the need of some further elaboration of the bald statement attributed to Galen of the self-revealing nature of time, that it is understood only in its own terms or 'made evident' through itself; and here Simplicius' suggestion that Galen's motion-independent understanding of time may be further understood in terms of the 'extension of being' (he tou einai paratasis) might be thought fruitful. Unfortunately, however, it seems that it must be distrusted, as it turns out that the phrase in question is one beloved of Simplicius, but very little attested elsewhere in Greek literature. The conclusion that it

19 Simplicius, On Aristotle’s Physics 4.11 (718,13-719,18 Diels) 
is Simplicius' own gloss, rather than a further quotation from Galen, seems unavoidable. ${ }^{20}$

In spite of these problems, however, and of the dimness with which Galen's original argument can be discerned through the murky thickets of a problematic textual tradition and hostile later scholarship, his attack on the Aristotelian definition, and the fundamental position attributed to him, of time as something only perceptible or measurable in its own terms, not by reference to place or magnitude, seems a distinctive and noteworthy one.

It should be added that there is a further piece of evidence that Galen argued for the conceptual independence of time and motion. Such a view is attributed to him by a tenth-century Arabic author, Ibn Abī Sa'īd: ${ }^{21}$

Galen's view was that time is eternal, and does not need motion to exist; and he states that Plato was of a like opinion on this point. That is to say that he considered that time is a substance, meaning by that duration, and that motion measures it. Galen states accordingly that motion does not produce time for us; it only produces for us days, months and years. Time, on the other hand, exists per se, and is [not] an accident consequent on motion.

Sorabji doubted the reliability of this testimony, preferring the view that Galen held that time could exist without orderly celestial motion, but not without motion altogether. However, there seems to be no explicit evidence associating Galen with that narrower view; and, more importantly, the view ascribed to him by Ibn Abī Sa'īd seems to accord perfectly with that which has emerged, albeit dimly, from our other evidence.

\section{Galen on time (2): further analysis and justification}

If, then, we have established Galen's theoretical position in broad outline, a little more should be said by way of elucidation of this position, as well as of its likely motivation and justification.

For the above passages from Themistius and Simplicius raise a rather obvious question, to which we may be keen to determine the answer. Is Galen grossly misunderstanding Aristotle, as Themistius impatiently suggests, or is Themistius failing to grasp Galen's legitimate objection and alternative point of view? In

20 The terminology perhaps finds a parallel in Augustine's understanding of time as an extension, in particular an extension of the mind (Confessions 11.26), discussed by Sorabji (1983): 301.

21 I here give the most relevant part of the text here, which was published by Pines (1955), to whom the translation is due, and discussed by Sorabji (1983): 82-3. 
what follows, I shall suggest that Galen's view at least deserved something better than the Aristotelian commentator's contempt and at best was a reasonable view for which he was able to offer a coherent argument - one, indeed, which we may find persuasive.

Themistius accuses of Galen of reducing Aristotle's statement that 'time is not without motion' to the banal proposition that 'we are always in motion when we perceive time' and then proceeding to argue that this banal proposition can have no force relevant to the point at issue. For, by virtue of the same proposition, we are always in motion, also while conceiving of things without motion. Thus, if Aristotle, as Galen claims, relies on this proposition for his view of time, he would by the same token have to argue that 'things without motion are not without motion': we are in motion while we perceive them, too.

So, according to Themistius, Galen has taken Aristotle to intend 'not without motion' to refer to the state of the subject or observer, not to an external object or state observed over a passage of time, and thus plainly to distort Aristotle's intention.

But is Galen's interpretation as crass as Themistius suggests? Or, to turn the question around, in what sense are we to take Aristotle's statement that time is not without motion, and might Galen's criticism of his view correspond to a coherent interpretation of it?

Let us say that Aristotle means that we cannot either perceive, or imagine, time passing without also perceiving or imagining some motion which takes place over that time. But any particular observed object, at least, may remain completely still during that period; there may be no observable motion. Surely that can be generalized, at least in principle, to the totality of things we observe over a given period of time. It is possible to observe an external state of affairs, at least over a very short period of time, in which no motion at all takes place, or at least one in which we are aware of no motion. (And it is certainly possible to conceive of oneself making such an observation or lack of observation.) There is therefore a clear conceptual separation; there can be periods of time which pass without observable motion. (We might, indeed, wish to say that the very fact that there can be more or less motion itself is sufficient to establish the conceptual separation.)

The counter-argument will presumably go roughly as follows. We are, nonetheless, constantly aware of some motion - if not of change as observed in the outside world, then at least of our own breathing or heartbeat. Well, Galen could say, these too could theoretically be stopped, at least for a short period. Perhaps, then, a mental motion is sufficient. This, perhaps, is the point on which Aristotle may be taken to rely. As we observed, he speaks (at Physics 219a4-7) of such a 'motion of the mind' in justification of his view. The passing of time, then, the 
Aristotle/Themistius argument goes, is only observed because something happens - a mental activity, which may be defined as a motion - and we measure or perceive time against that.

Against this, Galen's argument could reasonably take one (or both) of two tacks. First, to point out that the mental motion, too, is only contingently present: just like any observed external motion, it can be present more or less. Our argument in relation to external motions was that they may be absent, or so little present as not to be observed, and that therefore our perception of the passage of time cannot be taken to depend on them. But internal 'motions', of our body or mind, too, may be present to a greater or lesser extent, while the same amount of time passes; how then can we define time as inseparable from this kind of motion, any more than from the other?

Or (the second tack): why should we define the mental activity by which we have consciousness of time passing as a 'motion'? That is: we can imagine a mental state in which we are conscious of no motion - in the standardly accepted, spatial, sense - not even an internal motion 'of the mind'; but we would still be conscious of the passing of time. Of course, it is open to Aristotle to claim - and indeed he apparently does claim - that such mental consciousness of time passing is, indeed, a motion. But Galen might, surely, be justified in demanding some further argument in support of that claim. And, in the absence of any such further argument, in holding to a view that such mental awareness of the passing of time is not, itself, a motion.

Does it not, then, make sense to regard this mental awareness of the passage of time - so long as we have been given no good grounds for subsuming it under the heading of 'motion' - as corresponding to something that is definable in its own terms, and not in the same terms as those of motion - to state that it is 'made evident by itself', separate in kind from motion? To look at it the other way round: what justification is there for taking space or motion as the prior category, and regarding our perception of time as some derivative of it?

It seems to me that it is plausible that Galen's argument could have taken some such form as the above, even if not expressed in precisely those terms. It seems to me, further, that an argument along those lines is a convincing one, in leading to the conclusion that perception of time and that of motion are not, indeed, inseparable - or at the very least in casting doubt on that conceptual inseparability.

We have then an account of why Galen might - in my view, with reasonable justification - have asserted that time was 'made manifest only by itself'. In terms of the further structure of his lost argument, then, we can understand how on that basis he could have proceeded to an attempted reductio of Aristotle's position along the lines that 'we are always in motion when we think of mo- 
tionless bodies too'. It is, in Galen's view, Aristotle who is guilty of the confusion, because it can only be, on the best possible account of his theory, some motion internal to us which establishes that time is always with motion. But such internal motion may or not be present, or at least it may be present to a greater or lesser extent; its presence is therefore contingent and cannot be an intrinsic feature of time's passing. Since, then, the two are conceptually separate, and any motion going on within us is not directly or essentially related to the passing of time, Galen's reductio hits the mark. It is, of course, completely irrelevant to our mental conception of a motionless body that our own body happens to be in motion while we have that conception. But, as Galen's argument shows, precisely the same irrelevance applies in the case of time and motion, since all that Aristotle can coherently be taken to mean by 'time is not without motion' is indeed that there will, generally, be some motion going on while we perceive. That motion, on Galen's view, is just as irrelevant to the conception in the one case as in the other.

Whether or not we find Galen's view persuasive, however, it seems to have found few advocates within the ancient philosophical tradition. A partial parallel is perhaps found in Augustine, who, in an argument against the view that times are celestial motions, made the point that time would not be affected if the heavenly bodies either stood still or were accelerated; elsewhere, however, he does seem explicitly to accept the dependence of time upon change. ${ }^{22}$

On a broader perspective, Galen's view seems to find an echo in the modern 'substantivist' or 'absolutist' view, in philosophy and physics, according to which time is conceptually independent of those things which happen within time. In the early modern period, such a view is associated with Isaac Newton, and sometimes called the 'empty time' or 'bucket' view. ${ }^{23}$ A more recent philosophical attempt to justify the notion that the passing of time does not necessarily involve change was made by Shoemaker. ${ }^{24}$ It may be said that neither this nor the 'empty' view have been found widely persuasive in contemporary philosophy

22 Confessions 11.23; 12.8 and 11; City of God 11.6 and 12.16. The passages and Augustine's view are discussed by Sorabji (1983): 30-1.

23 It is also sometimes referred to as 'Platonism with respect to time', although, as has already emerged, this term is misleading. The attribution of such a view to Plato is, at least, disputed within the Platonic tradition: see n. 4 above.

24 See Shoemaker (1969); also Newton-Smith (1980), arguing for the possibility of 'empty time' but against the absolutist view. For an overview of philosophical views that time does or does not involve change, see Emery et al. (2020), section 2, with further literature cited there. Relevant to the ancient, including Galen's, discussions of the fundamental nature of time perception is also Prosser (2016). 
or physics, which rather emphasizes the fundamental inextricability of space and time. ${ }^{25}$

\section{Galen on speed: the measurement of the pulse}

We move to a more practical area, although here too we shall consider Galenic, and other medical, analyses of a theoretical nature, regarding both time and its relationship with motion. ${ }^{26}$

Galen's discussion of our perception of speed arises in the context of the medical assessment of the speed of the pulse. Here, as before, some filling-in of the complex theoretical background will be needed before we proceed further - in this case, the theoretical background concerning the discernible distinctions within the motions of the pulse, which were taken to be of great clinical importance.

Galen identifies five key variables in relation to the pulse: speed, size, tension, hardness or softness of the artery wall, contents of the artery ('fulness' or 'emptiness'). ${ }^{27}$ Two further complexities, or sets of variables, must however be added. One set arises from the internal relationship of the different parts of the pulse: 'in all these respects ... there will sometimes be evenness, and sometimes unevenness; and there will be some ratio of the time of the expansion ( $d i$ astolē) and that of the contraction (systolē)'. (For fuller explanation of Galen's physical theory of the diastolē and systole see below, p. 141 with n. 33.)

25 But the absolutist view of both space and time, i.e. the view of their existence independent of their contents, does form part of a debate in modern science; see Mitchell (1993).

26 On Galen's theory and practice in relation to the pulse see Barton (1994a), Lewis (2016); and for a broader, comparative perspective Kuriyama (1999). On the Galenic physiological background see Harris (1973), and for the most relevant pre-Galenic history of pulse theory see Lewis (2017) (on Praxagoras), von Staden (1989) and Berrey (2017) (on Herophilus).

27 Galen presents the different sets of variables in a number of subtly, and sometimes confusingly, different ways; and in particular he sometimes casts doubt on the validity of the category of 'fulness'; on these issues see Lewis (2022), (forthcoming). My summary here is based primarily on The Distinct Types of Pulse 1.3 (VIII.500-1 K.): 'There must, then, quite necessarily be [1] some time of these motions ... as well as some time specific to the periods of rest. Since the artery possesses three dimensions ... length, breadth and depth, it is absolutely necessary that there be [2] some quantity in each of the dimensions, both of expansion and of contraction. It is also necessary that it be in [3] some state of tension, so that it is acting either with difficulty and feebly, or readily and vigorously; and that [4] the actual tunic of the artery be soft or hard, but also [5] the internal breadth be as it were empty or full.' 
For our purposes this last-mentioned 'ratio' is of particular importance. The ratio between the two phases of the pulse, also known as the rhythm, is a crucial, and contested, diagnostic concept. In fact, there are, on a more precise analysis, four phases in the pulse: the expansion (E), the period of rest which follows the expansion before the commencement of the contraction (R1), the contraction (C), and the period of rest which follows the contraction before the commencement of the next expansion (R2). On this analysis, then, the ratio or rhythm will we that of $\mathrm{E}+\mathrm{R} 1$ to $\mathrm{C}+\mathrm{R} 2$. (This more precise analysis has another important consequence, as we shall see shortly.)

We have, then, covered all the distinctions that can arise - but only those which can arise within any one beat of the pulse. There remains a final set of variables.

For there are two other, 'systematic' distinctions, as they are known, whereby we consider the evenness and unevenness and the regularity and irregularity of a number of pulses compared with each other. ${ }^{28}$

These last two terms, then, 'unevenness' and 'irregularity', pick out discrepancies between the manifestation of one or more of the above variables in the first beat with their manifestation in the next, or later, beats.

Now there is something very striking that emerges here, especially if we wish to consider the Galenic project of pulse diagnosis in relation to its modern descendant. For under neither of the two broad headings - that of variables discernible within a single beat or that of variables discernible over a series of successive ones - has Galen mentioned the one variable in the pulse which is standardly assessed today: the rate of the pulse. Is this because pulse rate plays no part in his system? Yes and no. In fact, the conception of puknotès that is, how frequent, or how 'close together', the successive beats of the pulse are - did play an essential role in pulse diagnosis, for both Galen and other ancient medical practitioners (as we shall see shortly). ${ }^{29}$ That sounds

\section{See further the text cited on p. 142.}

29 When used in a temporal context, puknotēs could reasonably translated as 'frequency', in the sense of how often something occurs in a given time. In view of the difficulty, which I here outline, in equating the notion with that of 'rate' of the pulse, and the additional complication that 'frequency' in modern-day medicine has a separate, technical meaning in relation to the pulse, I for the moment preserve the word in transliterated form. 'Closeness' or 'density' provides a good approximation to the core sense of the term, which in Greek usually has a spatial reference, and is less commonly applied to time intervals. It is noteworthy that Galen himself claims that the fundamental sense of the opposed terms araios and puknos is that of porousness and the lack of it: something is araios if it is 'run through with large channels', and puknos if its 'run through with small ones', i.e. dense. It is from this physical sense, says Galen, that the others, including temporal frequency or scarcity, are derived (see Health 2.5, 53-4 Koch, VI.119 K.). 
very like the conception of pulse rate; it seems that it should yield the same result. In fact, however, the two conceptions are, for Galen at least, significantly different. Moreover, the difference is important and instructive.

Galen makes the clear distinction, just outlined, between differences discerned within one beat and those discerned over several. Yet he does not mention puknotēs - how close the beats are together - in the latter category. Puknotēs does appear; but it appears as a subcategory amongst the variables discernible within one beat. Specifically, it is a subcategory within the first such variable, namely 'time', i.e. the duration and speed of that single beat's motion (or of the parts of its motion). Yet surely puknotes - how close or frequent the beats are - is, by definition, a function of the relationship between successive beats? How, then, does Galen's apparently illogical and nonsensical categorization of it come about?

The explanation is in fact quite straightforward. ${ }^{30}$ On the most precise analysis, as we have seen, there are four phases of the pulse: the diastole or expansion (E), the period of rest after the expansion (R1), the systole or contraction (C), and the period of rest after contraction (R2). For Galen, the duration of each of these can and must be considered separately; and each is in principle measurable (albeit not, as we shall see, with complete precision).

Galen defines puknotēs in terms of the length, or shortness, of the interval between the end of one pulse and the beginning of the next. It is, indeed, the 'closeness' of one pulse beat to the next, understood in terms of the shortness of that interval between one end and the next beginning - that is, R2. We, by contrast, measure pulse rate in terms of a number of beats per minute; here the relevant interval must be that between the beats themselves, or more precisely between the precisely equivalent moment within each beat. Take a rate of 80 beats per minute: the relevant individual timespan is 0.75 seconds: that is, this is the length of time that elapses, on average, between one beat and the next, or to be precise between the equivalent moments within those two beats. Now, it might be thought that the difference between measuring the time between the equivalent moments within two successive beats, and measuring the time of the interval between the end of one and the beginning of the next, was trivial. In fact, it is of considerable significance.

On Galen's model, as we have seen, each individual pulse consists of four phases: E, R1, C, R2. Each element within that may be longer or shorter. It

30 For Galen's account of the fact (which he acknowledges is not universally agreed) that puknotès, although in a sense a feature of a set taken together, is indeed discernible within one beat, see The Distinct Types of Pulse 1.6 (VIII.511 K.). 
would thus, in principle, be possible for an E of very long duration, or an E + R1 $+\mathrm{C}$ of very long joint duration, to be combined with an $\mathrm{R} 2$ of very short duration. Conversely, the whole of the E + R1 + C might be completed exceptionally quickly, while R2 was unusually long. It will thus be readily seen that length of R2 cannot possibly be used to give a measurement that would equate to pulse rate. It could happen that the beats were puknoi - 'close' - in Galen's sense, but that the total number over a minute turned out to be unusually low. Conversely, a case where the beats were the opposite of puknoi (araioi, 'spaced out'), i.e., where R2 was quite long, would give a high reading per minute if the other phases, E + R1 + C, were exceptionally fast.

We shall turn to the question of the measurement of puknotēs - in fact, the only of these variables for which there is ancient evidence of some kind of quantitative project of measurement, using observer-independent apparatus - towards the end of the chapter.

For now, let us note a crucial conceptual point which has emerged from the above. Galen neither singles out 'rate', in the way that we would expect any clinical observer of the pulse to do, nor, in fact, does he have a distinct class of 'rate', separate from his observation of a single beat of the pulse. The result is striking. At one level, it is a function of a technical or semantic difference, in his definition of terms: he is able to subsume puknotēs, the variable corresponding to how frequently the beats recur, under the heading of length of time taken up by the rest at the end of the pulse beat. On another, it bespeaks a fundamental difference in scientific model and expectation. The problem or omission we perceive here - namely that there is nothing, on this model, that corresponds to our beats per minute - simply does not occur to Galen. It is no part of his project or ambition to give a quantitative measurement of the time periods in question, something which can only be achieved through such measurement of time over a longer period such as a minute, followed by division of the result of that measurement. Thus, for his purposes, the definition of pulse rate - or more precisely, of the 'closeness' between beats - in terms of the smallness of the interval between the end of one and the beginning of the next makes perfect sense, and leads to no conceptual oddity or problem.

Let us, then, leave both pulse rate and puknotēs to one side, and return to the first and fundamental set of differentiae mentioned above - those assessed within one beat. What does it actually mean to measure the speed, as opposed to the frequency, of a pulse? In general terms, Galen is clear what is meant by the speed of any object. It is understood - uncontroversially enough - in terms of the relationship between distance traversed and the time in which it is traversed. Galen gives a number of examples involving people traversing distances measured in stadia. 
Let us take it that there are two motions, one of which completes fifty stadia in one hour, the other 150 stadia in three hours. Should we, then, also say that these are equal in speed? Of course we should. ... Motions which cover an equal distance in an equal time will be equal in speed. ... If, on the other hand, the ratio of distance to distance is greater than that of time to time, or that of time to time greater than that of distance to distance, then we shall no longer consider the motions equal in speed. ... Let us say that there is one motion covering a distance of 400 cubits and another one of 100, while the time is two hours in the former case and one hour in the latter. ... Evidently if we imagine the former motion covering only the 100 cubits, it will do so within half an hour. It will thus be swifter than the second motion, since it covers an equal distance in a shorter time. If, meanwhile, we conceive of the second motion covering the 400 cubits, it will require four hours to do so, and so will be slower than the former motion, since it covers an equal distance in a longer time. ${ }^{31}$

Galen is never averse from labouring a point, and the above (abridged) account seems to make one which is simple enough - that both distance and time need to be known in order to assess speed - in a very painstaking and even roundabout way. Galen's laborious and circuitous examples, however, remind us of an important feature of such measurements in the ancient world. Longer units, both of distance and of time, are much more readily measured, in everyday life, than shorter ones. In the case of time, as was already observed in our first chapter, units shorter than an hour are problematic; in terms of distances, too, those most easily measurable will be the larger-scale ones, known or marked out in or between public spaces. This is not a world of readily accessible or portable instruments of measurement, of either distance or time. One result of this is that calculations of relative speed will tend to proceed on the basis of the kind of processes of division or multiplication of known or readily observable units outlined in this passage. In fact, nothing is being said, here, about the instruments by which these measurements are made; but the everyday examples Galen gives rely on a scale of measurement - in time, hours; in distance, longer units - that would be publicly available and accessible.

But the point of producing these examples is, for Galen, precisely to address the challenge of the measurement of the speed of the pulse. In principle, exactly the same applies here as there: one should know the distance covered and the length of time in which it is covered..$^{32}$ So, again, the motion of what, and

31 The Discernment of the Pulse 2.1 (VIII.830-3 K.).

32 The point is made explicitly: 'If we already know how great a distance the well-balanced pulse accomplishes in how long a time, and then in the case of another pulse, which has the same time, we find a shorter distance, we will say that the latter has been moved during a long time period ... we shall say that a pulse which happens in a short time is quick and one that happens in a long time is slow,' The Discernment of the Pulse 3.1 (VIII.880 K.). 
over what distance, is being measured when we measure the speed of a pulse? In order to answer this, we need to understand in a little more detail the Galenic conception of the motion of the pulse itself. Galen takes the arterial motion of the pulse to consist in a vehement outward motion or expansion of the artery - the diastole or expansion - followed by a return or inward motion, the systole or contraction. ${ }^{33}$ In the course of the outward motion or expansion, the artery is extended in three dimensions, and each of them - height (or depth), length and breadth - is potentially significant. And the amount of this extension is the size (megethos). The second variable is the forcefulness or vehemence (sphodrotēs) of the observed impact. The third is the speed. Speed must not, as already mentioned, be confused with 'closeness', puknotēs, on the one hand; nor do increases in speed go along with those in size, on the other. A puknos ('close' or 'frequent') pulse - not a fast pulse - is one in which successive beats occur close to each other in time. Two pulses may have exactly the same puknotēs and they may, further, have exactly the same size - that is, the point of maximum extension of the artery may be the same. But this point of maximum extension, as well as the return to the minimum extension, may be arrived at twice as fast in the one case as the other: this will be a difference in speed.

What has to be measured, then, in a measurement of the speed of the pulse is the time taken for the artery to reach that maximum extension, considered in relation to the distance moved by it in the course of that motion. The time and distance taken in its return to the unexpanded state may similarly be measured. $^{34}$ There is a period of rest, after both diastole and systole, which however

33 The terminology is potentially confusing in relation to modern medical usage, where 'systolic' and 'diastolic' refer to motions of the heart, the former motion - that is, the contraction of the heart valves - corresponding to the pumping of blood, the latter being the period of its relaxation and refilling with blood. In ancient pulse theory, by contrast, what is at issue is a motion of the artery, rather than the heart, and diastole and systole refer, respectively, to the artery's expansion and contraction. The diastole is the outward (in our terms, pumping) motion, the systole the relaxation or contraction, of the artery; and thus the sense of the two terms - as regards the phases to which they refer - is effectively reversed, in relation to our usage. In what follows, I shall continue to use 'expansion' for diastole and 'contraction' for systole.

34 In fact, there is lengthy Galenic discussion of the role of the systole or contraction in pulse assessment: this was a controversial question in the tradition on the pulse, with Herophilus and Archigenes asserting that it was perceptible and others, especially the Empiricists, denying it. Galen's view is that while the systole is perceptible, its perception and accurate discernment are performed only at a highly advanced stage of clinical practice, and are not available to all, not even to all doctors. (See e.g. The Pulse for Beginners 4, VIII.456-7 K.; The Discernment of the Pulse 1.1, VIII.770-1 K.) One may thus for certain purposes operate according to a simplified system in which one takes into account only the diastole. 
should not be taken into account, as what is to be assessed is the speed of the actual motion.

We are now reasonably clear, at least, what it is that is being measured, and what facts need to be discovered in order for such a measurement to made. But here we immediately come up against a problem, that of the technology or methodology involved: how, in practice, is any such measurement performed?

In fact, no non-human apparatus is relevant, from Galen's point of view. The technology of measurement is rather the human perceptual apparatus - in the context of the pulse, that is the sense of touch - which, however, can be brought by training to a high level of perceptiveness, discerning degrees of difference and indeed actual phenomena which to begin with are completely imperceptible. It will be worth offering a quotation from Galen's vivid and enthusiastic account of the development of such perceptual and analytical skills; the following passage also lists succinctly the range of detectable variables in Galen's scheme (already summarized above):

Sculptors and painters train their optical sense, wine-makers and cooks their sense of taste, those involved in the preparation of scents their sense of smell, and musicians their sense of hearing, not for days or months but for many years in order to achieve the necessary precision - and this in spite of the fact that they have the materials for this practice constantly available to them. How much time, then, should one imagine that a doctor requires for the training of his sense of touch? The doctor has to recognize a very large number ways in which the artery is affected ... first, he must recognize [1] the size of the dimensional extension, then [2] the quality and [3] the time of the motion; then, too, [4] tension of the capacity that moves them, then [5] the condition of the tunic of the artery itself. All these he must recognize simultaneously, during the expansion of the artery ... but the same range also during the contraction - and then there is the period which intervenes between them, while the pulse is at rest (which period is itself dual in nature, consisting of that which follows the expansion and precedes the contraction and that which follows the contraction and precedes the expansion), and the ratio between these two, that of the one period of the motion to the other and that of the one period of rest to the other, as well as that of the composite to the composite. All these must be recognized before the second beat of the artery, as the first pulse is completed. Then, as the second begins, you must examine the same things that were indicated in the first pulse, and compare the findings of that one with those of the present one, in order to identify their evenness or unevenness, and all the distinctions; then, you must consider three, four, five and indeed many successive pulses, in order to know their order or lack of it.

How long a period of practice do you think is needed for this? If I may state my own opinion honestly, I would say that a whole human lifetime is required to achieve perfect knowledge. ${ }^{35}$

35 The Discernment of the Pulse 1.1 (VIII.768-70 K.). 
He continues, via an autobiographical remark about the 'wonderful desire' that he nurtured, from an early age, for the art concerning the pulse, to discuss the debate amongst his predecessors (cf. note 34 above) about the discernibility or not of the contraction of the pulse, and his own related confusion. He continues in autobiographical vein:

I languished in this state of deep uncertainty for a considerable number of years; but I did not abandon the enquiry and, by constant application, I gradually acquired the impression of a contraction clear to the sense of touch. In the course of still further training, then, this ceased to be merely a faint impression; the discernment of the contraction became something as manifest as that of the expansion. Once this was established, it is difficult even to describe the speed with which I attained to the discernment of the remaining items; they followed at once, and from then on appeared quite clearly, as though a bright light had suddenly been shone in the dark. ... What happens is that a certain kind of attainment is being nurtured, the growth of which is so gradual and hidden that until it is fully formed it is not even evident whether or not it has begun; when, however, it does achieve completion it suddenly becomes apparent, producing the fruit of all the previous labours all at once and, if one may use a vulgar expression, with interest repaid. If those who came after me had even a small fraction of my devotion to these matters, which extends even to the attempt to communicate all the sensory experiences in words, then the art of the pulse could be acquired within a shorter period of training. ${ }^{36}$

A passage from another of the pulse treatises is also relevant to this understanding of the development and refinement of perceptual skill. Here too Galen elaborates on the notion of the ever-increasing ability of the trained senses to make relevant distinctions; and here too he makes a parallel with such technical training in another discipline, that of music. (See figure 14.)

... the well-balanced within each of the classes is single and indivisible; the others admit of a very large number of divisions, which are infinite in their actual nature, for distinctions of degree in every class ... must necessarily be infinite in number, but it is not so in our perception of them, which depends rather on our better and worse training, according to which we will be able either to recognize also the small distinctions or only the more prominent ones.

In the case of musical intervals, a musician will be well able to discern not only an interval of a tone or a semi-tone, but even that of a quarter-tone, while the lay person is not able to hear even an interval of two tones. ${ }^{37}$... in the present case, we have given an account of our

36 The Discernment of the Pulse 1.1 (VIII.771-3 K.).

37 Both these claims are perhaps less surprising in the ancient musical context than they might be to us. Quarter-tones were a feature of one of the standard Greek 'scales', the enharmonic, whose upward movement began with two such intervals. That same scale was then completed (up to the fourth) with the large interval of a ditone, while another of the standard scales, the 


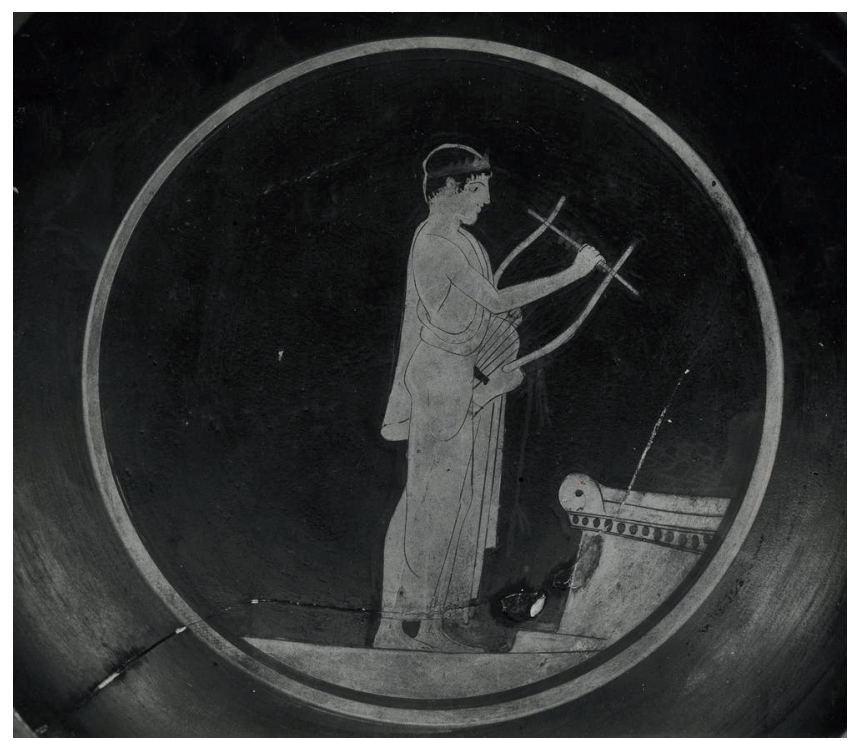

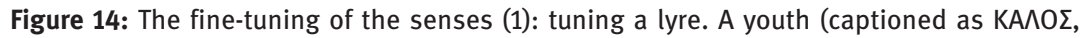
'beautiful') is depicted striking strings with his left hand while adjusting pegs with his right. From an Attic red-figure kylix, attributed to the Dish Painter (c. 490-470 BCE), British Museum, 1836,0224.168. Image source: https:/www.britishmuseum.org/collection/image/ 477213001 (C) The Trustees of the British Museum. Shared under a Creative Commons Attribution-NonCommercial-ShareAlike 4.0 International (CC BY-NC-SA 4.0) licence.

own perception: we are able to discern six distinctions of pulse by virtue of their excess or deficiency with respect to the well-balanced one, in each class. But it is sufficient for beginners, in the first phase, to perceive one such distinction in each case, and to be able to separate these from the well-balanced one. In the course of time, I suppose, and through practice, they will be able first, perhaps, to make a twofold division, then a threefold one and then a fourfold one. ${ }^{38}$

So, the measurement is one not carried out according to any absolute standard, but in a way relative to the individual perceiver. By the same token, that individ-

chromatic, included an interval of a tone-and-a-half. Relatedly, particular intervals, for example the lichanos or 'third', existed in many possible versions in different musical contexts, the different possibilities spanning a range of a tone. Thus, while the second of Galen's claims here seems exaggerated, at least for a person with any significant experience of listening to music, it is at least true that in certain contexts a rather wide range of frequencies could be heard as in some sense 'the same note'. (See further n. 56 below, with Aristoxenus' account of such broad pitch ranges.)

38 The Distinct Types of Pulse 2.8 (VIII.619-20 K.). 
ual may hugely increase his or her capacity to make the relevant distinctions and judgements.

But this still leaves us with a question. For if one is not using any measuring technology, nor attempting the kind of precision that this would involve, there must still be some mental or conceptual standard or scale involved, and this might be of more than one kind. For example, it could be that although not actually checking one's findings against any apparatus, nor aiming to offer any numerical account of those findings, one still has some system of measuring units in mind, of the sort that such an apparatus would provide. Another possibility is that the conceptual measurement is made by reference to no such independent standard at all, the scale being provided rather internally, by consideration and experience of the motions of the objects under examination themselves. And this latter alternative seems in fact to be the case.

That is, the observer or practitioner learns to gauge the speed (along with the other variable, size and vehemence) associated with human norms of various sorts - norms for the human species as a whole and, which is more relevant to actual clinical medicine, norms for a particular individual or class of individuals. Further specifications may arise in relation to age, sex, individual constitution, environment, and so on.

Such norms, then, are understood as constituting the relevant midpoint on each of the relevant conceptual scales. 'Large', 'small', 'vehement', 'faint', and so forth, must be understood not as absolute, nor as quantifiable, terms, but as qualitative assessments of a significant departure from that norm or midpoint. It is in virtue of its adherence to or departure from that human midpoint or mean that a mixture or state of the body, a drug, or a particular pulse, is assessed as 'medium' (or 'well-balanced', summetros), 'fast', 'slow', and so on. That is what, in such contexts, these terms actually mean. Galen insists on this point, of the relativity of the conception of all such quality terms - specifically, their relativity either to the normal human state in general, or to the normal state of a particular individual - repeatedly, for example in Mixtures and in Simple Drugs as well as in the pulse treatises. Further refinements can be introduced, on such a conceptual scale; however, they remain qualitative refinements, with no reference to a numerical scale of any kind.

It is noteworthy, indeed, that in the particular context of the pulse Galen actually warns against the ambition to found such judgements on a quantitative basis.

This [sc. whether a pulse is long or short] cannot be determined by the number of fingers, as is the practice of some, who say that it is long if it extends to four, medium if it extends to three, and short if it extends to two. For there is no single measure of best nature in a body; 
it is rather that by starting from one [individual] nature you will easily discover the quantity in each case, providing that you are capable of making an inference to the proportionate quantity. By comparing other human beings with that, you will say, in the case of those with a body of the same overall length, that they have a long or a short pulse. And similarly that they have a pulse which is wide, narrow, high, shallow, or large and small in all three dimensions, for in each case you will judge the others by reference to the point of good balance. $^{39}$

While this may sound terribly vague and subjective, from a contemporary scientific perspective, the ancient medical discourse is remarkable optimistic about what can be discerned by the trained senses - as indeed the above passages make abundantly clear. ${ }^{40}$

There is a further, specific ramification of this, when it comes to the measurement of speed. As we have seen, Galen lays out a clear definition of speed, in terms of distance over time, which seems in theory to correspond to an ambition to give precise measurements of each of these; and indeed, in certain cases, with longer distances and longer time periods, such precise measurements would have been perfectly available to him. When it comes to assessment of speed over very short time periods - those relevant to the pulse - there is no such precise measurement suggested, even in principle. In fact, very shortly after the passage cited, in which Galen describes the assessment of the speed of a pulse in terms of a knowledge of both the distance covered and time elapsed, he produces a quite different account of the nature of our actual assessment of speed - one which is entirely qualitative in nature.

We recognise speed and slowness in the first impulse of the artery, but need a great deal of time to discover the relationship between one time and another and one distance and another. So, we do not wait to calculate them for the purpose of the diagnosis of the sick; when we observe something before us, the rush of the impulse is sufficient to indicate its speed; so it is with the artery - one may find that its motion is rushed or relaxed. ${ }^{41}$

A little further on he adds:

39 The Discernment of the Pulse 3.2 (VIII.889-90 K.)

40 One may compare also a striking passage from the treatise Mixtures, where Galen recommends a procedure of comparison of the temperature of bodies at different ages, as discerned by the touch, even suggesting that such a comparison can be carried out in relation to the same body at different ages, with the relevant tactile experiences in some way mentally stored and used much later in the process of such comparison: Mixtures 2.9, 52-3 Helmreich (I.590-2 K.). See the commentary ad loc. of Singer and van der Eijk (2018); and further van der Eijk (2015b).

41 The Discernment of the Pulse 3.1 (VIII.882 K.). 
The above, then, will be sufficient as indication of the fact that we do not investigate the quantity of the time and distances, but the quality itself of the motion. This is admittedly difficult to express; but if you take what has been said as a basis, and are not completely incapable and useless, you will arrive at the truth without difficulty, in as far as human capacity allows. And even more so, if you practise the discernment of those pulses which are uneven in respect to speed and slowness, you will find that their coming about consists in the quality of the motion. So, for example, in one expansion the starting point of the motion often appears manifestly swifter, but what follows appears slower, and then again the extremity swifter, although we are not measuring certain quantities, whether of times, capacities or distances, but only investigating the quality itself of the motion..$^{42}$

Here, speed is discerned through an immediate perception: quality, quite explicitly, replaces quantity in the mental procedure.

It is noteworthy here that Galen at times explicitly categorizes the variable of 'time' or 'motion' within the pulse under or together with the heading of 'quality', as distinct from 'quantity', which applies to the size of the expansion; see for example the passage cited on p. 142 above (though of course, as we have already seen, 'quantitative' assessment in a modern sense is not applicable to the 'quantity' variable of the pulse, either.)

A couple of other things are worthy of note in these passages. One is the emphasis on 'unevenness' in the latter. What Galen means by this term is an inequality between different parts of the pulse. What is apparently stated here, then, is that it is easier, in these qualitative terms, to discern a difference or mismatch between one phase of the motion and another - to make another kind of relative measurement, that is - than to make statements about speed in isolation from such a comparison. Another is a point about the immediate context of these remarks. In the passage immediately preceding the last passage quoted, Galen has given an analysis of perception in terms of primary or minimal perceptible units - an analysis to which we shall turn in a moment - before summing this up with the remark: 'these matters are better philosophized about separately ...' He then turns, as it were, from that 'philosophizing' to the more practical, experiential account of the clinical experience of pulse speed measurement.

The passages just considered may strike us as vague and unsatisfactory. It should, however, be observed that such subjective or immediate perception of speed - again in conjunction with experience, with highly trained senses - is of course all that is available to one in the absence of sophisticated measuring apparatus; that in a number of relevant contexts no such measuring equipment was available until very recent times indeed; and that before its advent professionals in a number of fields to which speed assessment is crucial - sporting

42 The Discernment of the Pulse 3.1 (K. VIII.885-6 K.). 
and musical, for example, as well as medical - would make such judgements, with a high degree of skill informed by fine-tuned sense training. Indeed, in certain such contexts professional skill and judgement will continue to rely on such assessments, even when quantificatory apparatus is available.

Let us very briefly consider two kinds of example from our contemporary world. First, a modern-day sportsperson - a tennis player, for example, or a cricketer - has always been, and remains, able to make fine judgements of the speed of a particular serve or ground stroke, or of a fast bowler, both in relative terms (X is faster than Y; Z is serving at her fastest today; that was X's slower/ faster ball), but also in the terms most relevant to the performance of that sportsperson's skill. That is, such a sportsperson acquires an advanced level of ability to assess which servers, returners or bowlers are fast, medium-paced or indeed exceptionally fast, insofar as those terms relate to that sportsperson's ability at, or difficulty in, playing the balls received. Secondly, in music, any professional or even reasonably experienced amateur - performer has a highly developed sense not just of relative tempo but of the correct tempo appropriate to a piece of music in a specific genre, as well as an ability to double or halve that tempo, or to perform other subtle transformations of it. There is an internal operation here which has a high degree of accuracy.

In neither case is any technological apparatus - Hawkeye, or a metronome required to enable the performer to carry out those assessments, or the related motor responses, successfully; where these are available, they will in many cases confirm the accuracy of those judgements.

The same applies, even more strongly - as indeed Galen seems to hint in the passage just considered - to the assessment of the proportion or ratio between different time units, that is, to the relative assessment of speeds or time periods which is that involved in the assessment of rhythm. We shall return to this point shortly.

\section{Minimal units of time (1): the atomic nature of time perception}

We turn now to a further aspect of Galen's discussion of the assessment of speed - that, indeed, which we saw just now he sums up as a 'philosophizing' on the subject. This is his employment of the notion of minimal - or primarily discernible - units of time.

The conception is to be understood in the context of his attempt to deal with a larger question, which could be summarized as that of the relationship between the raw data of sense perception and our mental processing of them. 
For Galen is aware of the problem of the extent to which mental processes or suppositions supply the gaps in the actual content of our perceptual experiences. At one point Galen characterizes the difference as that between things primarily and secondarily perceived.

\begin{abstract}
The primary objects of our perception are the experiences within our own bodies; secondary are those which are productive of these, and which underlie them externally. We have a primary perception, in the case of the vehement pulse, of the motion which takes place in the touching parts, as the artery moves away after the pressure; and by virtue of this we state that contraction of the artery is accessible to perception: here, it is accepted that those factors which are productive of the actual experience may be themselves referred to as perceptible. ${ }^{43}$
\end{abstract}

What Galen is doing, here, is making a point about the fundamental nature of human perception - about how we register, or make sense of, the data available to us in sense perception, and the extent to which this process involves a mental inference from the 'raw data' actually picked up by our sense organs.

The particular relevance of this to the discernment of pulse motion is that one cannot (at least in the above, 'primary' sense) discern the whole of the motion of the pulse. The problem is discussed at some length in book 1, chapter 8 of this same text. There is a part of the expansive motion of the pulse which 'eludes perception', both at its beginning and at its end. The motion starts from nothing and at some point becomes strongly perceptible; it seems to be almost a logical consequence of this that there is a time at which the motion has started but is not yet perceptible. One is thus involved in inferential processes, in determining the exact time at which the expansion ends and the first rest starts, and similarly the time at which the first rest stops and the contraction starts. (The problem is even more acute in this latter case, as the contraction is not in any case perceptible in all kinds of pulse - nor, to be sure, as we have seen, by all practitioners.)

There is a part of that motion which is so faint that it escapes actual sense perception, so that we do not, properly speaking, perceive the full extent of the motion and the actual moment at which it comes to an end, but we are able mentally to supply the gap. Similarly, with a motion away from our finger, a loss of pressure: we do not, properly speaking, perceive this motion; nevertheless, through a combination of sense stimuli and inference, the nature of the motion is clear to us.

Galen's use of the concept of minimal units of time, space and motion is connected with this analysis. Our perception of both the passing of time, and the

43 The Discernment of the Pulse 1.5 (VIII.793 K.). 
movement of objects in space, he argues, is an important sense atomistic - there just are minimal units that we actually perceive, in space, time or motion. This is true in spite of the fact that time itself - like the fabric of the universe itself - is in reality (pros phusin) continuous.

In book 3, chapter 1 of The Discernment of the Pulse, Galen talks of 'the impression provided by sense-perception with regard to the discernment of the fast and slow pulses'. He says:

it is evident [to the senses] that the one readily leaves the places in which it occurs on each occasion and that the other remains there longer, and that the former is, therefore, called swift and the latter is called slow on account of the [nature of the] transitions from places; for sense-perception forms its discernment not in relation to the time of the entire motion, either considered individually and on its own or on the basis of a quantitative comparison. In this respect, our discernment of speed and slowness comes about immediately: it would not come about if we waited to grasp the quantities of the times and distances and then investigate the relations between them, which of course we do not. ${ }^{44}$

That much reads like a prelude to the discussion of the immediate and qualitative nature of our impression of speed which follows a couple of pages later in the text, and which we have already considered. But there is a further, more theoretical, element of the account, which is worth reproducing here in full:

At the [moment] of the first application of the sense of vision we use some inexpressibly short period of time in order to distinguish the staying in place of the body in motion, and on the basis of that we infer the transition. So, for example, with things that we see from afar, we sometimes have the impression that these remain for a longer time, even if they are moving very fast, and from this it is evident that we distinguish the motion by inference, not by sense-perception. For when any one of the primarily perceptible parts of the body in motion remains in the primarily perceptible place for a primarily perceptible time, then the object seen will seem to be unmoved; but when the primarily perceptible part remains in the primarily perceptible place for a shorter time than that which is primarily perceptible, then it will seem to be in motion. For although in reality each of the things mentioned is capable of being divided ad infinitum, in terms of our measuring them by senseperception they have certain primary and indivisible parts; and from this it is evident that all motion is discerned by inference not by sense-perception. But because of the fact that the inference is closely connected to the sense-perception and the fact that the transition performed by the mind is very fast, it very often seems that the discernment is made not by inference but by sense-perception.

It is only in the case of those things of which the primarily perceptible part remains in the place primary to perception for that time which is primary to perception, that we agree that we are manifestly grasping their motions by inference, not by sense-perception. Examples

44 The Discernment of the Pulse 3.1 (VIII.883 K.). 
are the shadow of a gnomon, the moon, the sun, all the stars and any other things which are most distant from us. But, on the other hand, as stated, when the time is shorter than that which is primary to perception, both the stay and the departure from the places appears to be without duration; for everything which takes place in a time shorter than that which is primary to perception gives the impression of being without duration..$^{45}$

Both space and time are, for Galen, infinitely subdivisible. Our perception, however, takes place on the basis of minimal units of each, below which it does not go. What is happening in our actual perceptual apparatus, at the most granular level, in our perception of motion, is that we discern an object at point X1 and then discern it having ceased to be at point X1 and appearing at point X2. We do not actually discern it in motion: the motion is something that we infer on the basis of its disappearance from X1 and appearance at X2. And an analogous procedure applies to our perception of the passage of time. What Galen is saying might be elucidated by an anachronistic example, that of frames in a film. Even though any motion, and the time in which that motion happens, are in their nature continuous, not atomistic, our own perception of both the motion and time is best understood in terms of frames - units than which we cannot perceive anything smaller. Our perception of motion, and therefore of speed, comes about through our registering of the quick succession of these frames.

Of course, most of the time we do not realize that this is what is happening - that our minds are in some sense supplying the impression of motion, whereas all we see are frames. This is why Galen introduces the examples of distant, or of very slow-moving, objects, to illustrate the principle. Here - for example in the progress of a shadow around a sundial - we may stare as long as we like, but we will not perceive a motion; we will, however, after some time see that the shadow has moved from one place to another. Here, then, we infer that there has been motion; and in this case we are conscious of the fact that we are making an inference. In normal cases of motion perception, Galen is saying, we are also making such inferences as part of the perceptive process, but this is happening at a subconscious level.

So, Galen's concept of minimal units of space and time belongs within his account of the fundamental nature of sense-perception, and relates to phenomena which take place at the most microscopic level, as it were at the edge of our consciousness of the perception. It is part of his account of the relationship between the role of the sense organs and mental inputs in our sense-making. ${ }^{46}$

45 The Discernment of the Pulse 3.1 (VIII.883-5 K.).

46 These issues are further explored in Singer (2022). 
As a coda to this theoretical discussion of minimal time units in Galen, and its relationship to his view of time as in its nature continuous, it is interesting to consider the later arguments of the Platonist philosopher Damascius. Damascius seems to have combined an account of time 'leaping', rather than moving continuously, with the view that such leaps are divisible, and in fact infinitely so. The combination of ideas is challenging, and detailed interpretation beyond our scope here. It seems, however, that he argued that time was in its nature divided into parts, but conceptually infinitely divisible - thus in a sense reversing the Galenic picture of a continuum in nature which our human perception translates into an atomic structure. Damascius is here addressing the problem of the relationship of the 'now' to the flow of time, with the related paradox - a feature of the debate from Aristotle onward - of the ceasing instant, or of how the present turns into the past. ${ }^{47}$ His discussion is thus fundamentally conceptual in nature, whereas Galen's is fundamentally concerned with the nature of our perception; but the parallel, and indeed reversal, provide a point of curiosity, at the very least.

\section{Minimal units of time (2): the analysis of rhythm}

The notion of minimal or 'primary' time units arises also in a different context, however, which is also worthy of our attention: that of the analysis of rhythm.

Both Galen and his predecessor in pulse theory, Herophilus of Chalcedon, were concerned to measure the rhythm of a pulse. Although there are differences of detail, essentially the rhythm of a pulse is understood as ratio, namely that between the time taken by the expansion and the time taken by the contrac-

47 Damascius states that 'time always flows, and progresses by leaps (halmata), in accordance with the nature of a progression by intervals', that 'these leaps are measures of time, defined by demiurgic divisions (dēmiourgikais tomais)' and that the now 'is so called not as a limit of time but as time which is demiurgically indivisible (ameriston), even if it is divisible in our conception - and that infinitely', Doubts and Solutions on Plato's Parmenides, III.191-2 Westerink and Combès (II.241-2 Ruelle). For discussion see Sorabji 1983: 55-6. Combès understands the expression 'demiurgic divisions' (that is, divisions due to the creator or original creation of the cosmos), which occurs also in Damascius' Doubts and Solutions on First Principles (II.178 Westerink and Combès, I.198 Ruelle), as derived from Plato's account of the construction, and divisions, of the world soul at Timaeus 35b4-36d7; in any case the sense must be of a division which is intrinsic to the object, as distinct from what is brought to it by our conception. The context of this passage is a commentary on the discussion of the relationship of the One to time in Plato's Parmenides, and within this Platonist framework Damascius is also exercised to give an account of time which in some way combines being and indivisibility with coming-to-be and motion. 
tion. ${ }^{48}$ Herophilus in fact seems to have paid particular attention to this feature of the pulse, and Galen follows him in this, while criticizing him in detail..$^{49}$

In a way which recalls our discussion in chapter 2 of the medical understanding of four main phases of life, Herophilus identified a normal pulse rhythm, as well as a normal pulse speed, and a normal pulse frequency, for each of these four ages.

Within those, we shall focus here especially on the question of the assessment of rhythm, while that of puknotēs (which we already encountered) will receive its own discussion below. But a little should be said about the assessment of speed, too, as the interpretation of Herophilus' theory here is of relevance to a broader question of the nature of the standard or objective basis of measurement which is a recurrent problem for us in this chapter.

For the question arises here, what level of normalization is in play. In stating that there is a speed, frequency or rhythm of pulse that is normal for children, is Herophilus referring to a norm that should be taken as applying universally, to all children of a certain age, or is he rather at pains to identify the normal speed (etc.) for each individual child? The parallel with the discussion of $p u$ knotēs, where it seems clear that Herophilus does indeed posit a norm - and in this case, an objectively measurable one - of universal applicability to all individuals of a certain age, in conjunction with the arguments of Berrey, suggests that we should favour the former interpretation. ${ }^{50}$ If that is correct, then it seems that, at least theoretically, that speed might be expressible as a definite quantity, and not only in terms of the observer's impression; and the discussion of frequency below suggests that Herophilus might in principle have had the ambition to provide such objective measurements. If this is right, then even though there would seem to be strong limitations on the feasibility of such measurements in the ancient context, the ambition of Herophilus to perform them would constitute a significant difference between him and Galen - and doubtless part of the background to Galen's attack on him for excessive claims to precision, which we shall come to shortly.

48 According to the more precise analysis mentioned above (pp. 138-9), the ratio in question is in fact that of the whole time taken by the expansion plus the former rest period (E + R1) to the whole time taken by the contraction plus the latter rest period $(\mathrm{C}+\mathrm{R} 2)$. It seems that Herophilus' account does not include mention of the periods of rest; at least, Galen repeatedly accuses him of confusion or unclarity as to whether it is included or not (see especially The Discernment of the Pulse 3.3, VIII.911-12 K.).

49 For detailed interpretation of Herophilus' views in this area see Berrey (2017); fundamental for the text and interpretation of the testimonia to Herophilus is von Staden (1989).

50 Berrey (2017): 200-1. 
Let us turn to Herophilus' account of the differential pulse rhythms to be found at different ages. Summarizing and combining the evidence from two main testimonia, we may paint the following picture: Herophilus connected each stage of a life with a different rhythm, and in doing so drew closely and explicitly on the terminology of musical and metrical theory. Each phase of life corresponds to one of the four rhythms, pyrrhic $\left(\ulcorner)\right.$, trochee $\left({ }^{-} \longleftarrow\right.$ ), spondee $\left({ }^{-}\right)$, iambus $\left(^{-}\right)$, where the first beat in each case corresponds to the expansion of the pulse, and the second to its contraction. Secondly, he equated the expansion with the metrical or musical term arsis ('upbeat') and the contraction with the thesis ('downbeat'). Thirdly, again following metrical theory, he understood the units underlying these rhythms in terms of 'primary time units': a metrical short syllable corresponds to one unit, a long syllable to two. ${ }^{51}$ Thus, the pulse in the newborn consists of two units, that of the youth and the postprime or old person to three units, that of the prime to four units.

In spite of his own adoption of the theory of primary perceptible time units in a different context, already noted, Galen has considerable criticisms of Herophilus' theory here. One point of departure seems to be that although Galen does discuss the importance of the relationship between the two main parts of the pulse, Herophilus gives this notion of rhythm much more prominence and technical importance in his system. Though complete clarity about Herophilus' system, and therefore about the nature of Galen's criticisms of it, is impossible, it seems too that Herophilus claims both a level of precision, and a universalizability, for his time units, which Galen rejects.

Part of Galen's criticism is undoubtedly based on his view, already discussed, that it is impossible precisely to discern the pulse throughout its entire duration: a part of it eludes perception. This throws doubt on Herophilus' project of providing precise mathematical proportions for each pulse. Moreover, he takes Herophilus to be unclear and probably inconsistent about the parts of the pulse: is he taking into account the periods of rest, or not (see note 48 above)?

51 The two passages are Rufus, Synopsis on the Pulse 4, 223-5 Daremberg and Ruelle (von Staden 1989, no. 177 and Galen, Synopsis on the Pulse 12, IX.463-5 Kühn (von Staden 1989, no. 183). There are some difficulties in detail of interpretation (especially the characterization of the newborn's pulse as alogos, 'without ratio', attributed to Herophilus in the former text), as well as differences in detail (for example the mention of arsis and thesis appears in the latter text but not the former; the latter attributes to Herophilus the terminology, already encountered above, of 'primary perceptible time units', whereas the former says only 'primary time units'). Part of Herophilus' claim here, at least on the basis of the second text, seems to be that the primary time unit is itself established on basis of observation of the newborn child. 
The latter point - Herophilus' unclarity on parts of the pulse - certainly forms part of Galen's criticism at the end of the second of our main testimonies. Here he states that Herophilus' equation of the newborn's pulse with two equal time units is consistent with his measuring the contraction from its beginning, whereas in his claim that the contraction of the pulse in old people can extend as far as ten primary time units, he must be counting the contraction from the end of the expansion, that is including the whole period of the rest as part of the contraction.

The former point, meanwhile - the impossibility of discerning the duration of the pulse in its entirety - seems to underlie his criticism of the Herophilean account in another passage:

\begin{abstract}
Why, then, did Herophilus assume some primary perceptible time by measurement against which he says that the other times are two, three or more in length, either in terms of units which are complete and, as they themselves call them, 'non-lengthened', or in units which are slightly, considerably or very much increased? For he seems to write this as though he were discerning the times in the cases of all the pulses precisely, either the times of the motions alone or also of those of the periods of rest after those times (for this makes no difference in relation to our present difficulty) ... ${ }^{52}$
\end{abstract}

Both from this passage itself and from its preceding context it is clear that part of Galen's issue is with Herophilus' implicit claim to be able to measure the time lengths precisely, as a basis for the establishment of the 'rhythms'. To put it simply: Herophilus cannot perform the measurements in the way required by his system. There is, perhaps, a further criticism too, of the Herophilean ambition to produce precise mathematical proportion. That is: even if Herophilus could produce the precise measurements in the way that would be needed, he would be wrong to believe that what will result is a series of neat mathematical ratios. This (Galen would be arguing) is an inappropriate attempt to impose a mathematical or musical system on the observed reality. The clinical reality is messier and more nuanced.

This latter interpretation of Galen's criticism is perhaps supported by the following passage, from another of Galen's pulse treatises, where - this time without reference to Herophilus - he outlines the notion of the rhythmic relationship of the expansion and the contraction, again making reference to mathematical proportion:

This [sc. the inequality of the expansion and the contraction] arises sometimes in virtue of an expressible difference, sometimes in virtue of an inexpressible one. There are two ways in

52 The Discernment of the Pulse 3.3 (VIII.913 K.). 
which it may be expressible, either as a multiple, or as a ratio between numbers, [of the sort] known also as an epimoric ratio..$^{53}$ Multiples are: double, triple, quadruple, and so on. Ratios between numbers [arise] where to an expansion which lasts two units of time there corresponds a contraction which lasts five, seven, nine or eleven. There is then a threefold distinction within the whole [category] of the inexpressibles overall: for either the time of the expansion is inexpressible, or that of the contraction, or both. Each of these individually sometimes has the inexpressible times augmented slightly - whether there is a plurality of these, or whether there is one primary one - and sometimes to a greater extent and sometimes to the greatest extent. And of course, 'primary time' should not be understood in terms of its actual nature, but with respect to our sense-perception. For this is how it is with musicians too. ... ${ }^{54}$

There is a certain amount that is not perfectly clear here, and up to a point at least Galen could here be taken to be summarizing the system elsewhere attributed to Herophilus. But he mentions a range of possible proportions beyond those explicitly attributed to Herophilus; and the 'inexpressibility' mentioned seems best taken in the mathematical sense, whereby an 'inexpressible' difference is one which cannot be reduced to a ratio between integers. The alternative would be to take 'inexpressible' here as simply meaning 'unquantifiable' or 'uncertain in extent'. On either interpretation, Galen is again expressing himself sceptically in relation to the neat simplicity which is the ambition of the Herophilean. The latter represents a distortion of the full range of empirical realities.

Before concluding this section it will be helpful to return the theoretical account of Aristoxenus, and investigate in more detail his account of the role of the minima, or 'primary time units'. This seems to constitute an important part of the theoretical background to the discussions that we have been considering; and the points of contact as well as departure will be instructive.

Time is divided by 'rhythmizables', within each of its parts. There are three such 'rhythmizables': speech (lexis), song (melos) and bodily motion. A 'primary time unit' (prōtos chronos) is one which cannot be divided by any of the rhythmizables. ${ }^{55}$

53 The usual context of this terminology was Greek music theory, where an epimoric ration is typically understood as one which takes the form n:n+1 (see Barker 1994: 117); in more general terms, it is defined as a ratio between numbers where the larger one contains both the smaller one and a simple fraction of it; cf. John Philoponus, On Aristotle's Posterior Analytics 13.3, 160, giving as examples the ratios 2:3 ( 3 is the sum of 2 and one-half of 2) and 3:5 (5 is the sum of 3 and two-thirds of three). Galen's usage seems consistent with this, provided that we include improper fractions (e.g. 7 is the sum of 2 and five-halves of 2).

54 The Distinct Types of Pulse 1.8 (VIII.516-17 K.).

55 Aristoxenus, Elements of Rhythm 2.9-11, 6-8 Pearson. 
Here it seems clear that a prōtos chronos is to be understood as context-dependent: it is a unit established in each case in accordance with a particular kind of motion, musical performance or speech act. We are not here talking about a standard or unit with any kind of universal applicability; the standard is set and established within a particular performative context, then used as a basis for further measurement and assessment within that context. A letter is the minimum unit of speech, as a particular motion, for example in a dance, is the minimum unit of bodily motion, and the primary time unit is that taken for the performance or utterance of any such minimal unit. The actual time span corresponding to the primary unit will, however, vary from case to case. But whatever the length of that established primary unit, all further patterns of time, and in particular rhythms, within the performance or utterance will be based on that unit.

Aristoxenus' discussion could be interpreted as relevant to both Galen's account of the physiological limits of human perception - there simply are units below which we cannot perceive - and of the Herophilean one, which is concerned rather with the construction or recognition of rhythms, for example by a musician or a doctor, on the basis of acknowledged and recognized minimal units established in a particular context. It is the latter analysis which is relevant to the discussion of rhythm. Neither Aristoxenus in his description of a minimal time unit in the sense relevant to the establishment of rhythm, nor Herophilus in his use of this conception in this context, need be concerned with a universal human constant. It is within the individual musical performance, or - in the context relevant to medical diagnosis - the individual bodily motion, that the norm, that is, the relevant 'minimal unit' is established, as a kind of analytical building block.

The assessment of rhythms is conducted in purely relative terms (whether or not that is the case for the assessment of speed and of frequency, as already discussed). All that is at stake with the measurement of rhythm is that we can make a mental assessment of two time periods and on that basis establish the ratio between them. Of course, the question still arises as to how, mentally, the assessment of time units that go to make up the rhythm in question is performed. Again, however - as in the discussion of the 'immediate' or qualitative assessment of speed, above - that is a question that arises today as much as in the ancient world. Such assessment of the relationship between two (or more) time units is an absolutely standard feature of music-making and indeed music perception. The mathematical relationship between two short time lengths can be, and regularly is, assessed to a high degree of accuracy, without the involvement of any independent measuring device - or even any objective metric - to measure the length of the time units involved. 


\section{Summary on minimal time units in Aristoxenus, Herophilus and Galen}

On the basis of the above, it seems that Galen's 'primary perceptible times' perform a significantly different role from those of Aristoxenus. Galen's main use of the conception is in the context of his account of the nature of our interconnected perception of time, motion and speed, where his central claim is that there are, from the perceptual point of view, minimal units of both time and space, and that our perception of motion and speed arises from the succession of these.

'Primary times' in Aristoxenus are, to the contrary, units chosen arbitrarily, or in certain contexts, on the basis of which other time units, in particular rhythms, are constructed. They are in no sense constants of, or in themselves intrinsic to, human perception. (Galen's use of the term in the last passage cited from him, pp. 155-6 above, may perhaps be taken in this sense rather than in that observed in his account of the perception of motion.)

In Herophilus, meanwhile, though the situation is less clear, it seems that 'primary times' are, at least in some contexts, taken as universals not just of human perception but of human physiology: they are (perhaps) universals, and correspond to the smallest duration observed in the phases of the pulse, in childhood and then in subsequent ages. They can also be taken as fundamental - in a way that Aristoxenus or Galen might also accept - in the construction of rhythm, but Herophilus apparently accords them a universalizing status, as well as a level of precision in the way they can be employed, which Galen certainly rejects.

In conclusion, I suggest that our analysis so far has pointed to a rather close parallel between Aristoxenus and Galen in their scientific procedure, in particular in the way in which they both use mathematical models.

It is noteworthy that both Aristoxenus and Galen are continuum theorists: for them atomic units, or minima, are pragmatic constructs which help to explain certain aspects of reality, or how we measure it. Aristoxenus' 'primary times' are not, any more than Galen's, intrinsic features of the physical reality. Rather, they are of pragmatic use - indeed absolutely necessary - for us, as practising musicians. They are intellective or conceptual tools by which we divide, and make sense of, time. ${ }^{56}$

56 Aristoxenus' combination of continuous with non-continuous concepts is perhaps still clearer in his theory of pitch intervals, which provides an instructive parallel, even if it takes us some way from notions relevant to time. Here, departing from the Pythagorean tradition which was only concerned with intervals understood in terms of precise points, given by mathematical proportions, Aristoxenus states that the number of pitches available between any two other pitches 
A broader intellectual or strategic similarity between the two authors may be suggested. Both are fundamentally concerned, not with theoretical or mathematical entities, but with observable and practical realities - musical on the one hand, medical on the other. For both, the mathematical model or calculation, to the extent that one is used, is a heuristic tool to enable the practitioner to carry out observations, or performances, in a way appropriate to the underlying reality, which is not itself an abstract mathematical object. In this context, Aristoxenus departed from a whole tradition, the Pythagorean, which took numbers and mathematical models to be the prior entities, insisting rather on the priority of the heard reality, in relation to which the mathematical model offers a tool of some, but limited, usefulness and validity. ${ }^{57}$ Galen departs from the apparently Herophilean insistence on the mathematical model as something which offers a precise correspondence to the reality of rhythms manifested by the human body; for him such a model can be at best an approximation, and its use is subordinate to the informed fine training of the senses.

\section{An isolated case of quantification? Pulse rate and the water-clock}

In all the above the question has arisen of the benchmark or standard against which any measurement of time units, or of speed, might be made; and we have repeatedly found ourselves in a conceptual world in which there is no absolute or independent standard of measurement, let alone measuring apparatus.

And yet there is one apparent exception to this for which we have evidence in the ancient sources.

is potentially infinite. The view has strong practical and aesthetic consequences. It is not just that the lichanos, for example (roughly equivalent to our 'third'), can be pitched at several distinct points over the range of a whole tone, in accordance with the different 'kinds' (genē, roughly 'scales'). It is that that range is, in theory, infinitely subdivisible: there is theoretically an in-

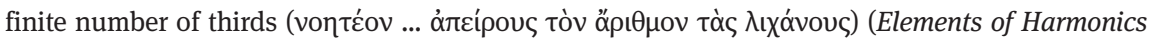
1.26). All notes within such a range will be heard as, and should be defined as, thirds, though they will all be subtly different thirds. He also, however, identifies a unit arrived at by precise mathematical division, namely that of a twelfth of a tone, which may be used to provide a mathematical solution to the problem of the consistent calculation of intervals (1.25). This precise mathematical division does not correspond to any 'real' musical entity, and in a sense divides the musical spectrum in an arbitrary manner; but the minimal units thus arrived at are again of practical use to the musician in the calibration of larger intervals.

57 For analysis of Aristoxenus along these lines see Barker (1978), (2005); Litchfield (1988). 
In the context of an account by a later medical author, Marcellinus, of his approach to fever, Herophilus is said to have identified excessive size, vehemence and frequency (puknotēs) ${ }^{58}$ as key diagnostic signs. Frequency, indeed, takes on a particular prominence in another testimony for the theory and practice of Herophilus:

Frequency of the pulse is first established ${ }^{59}$ when the fever starts and remains until the final dissolution. A story goes that Herophilus placed such confidence in 'pulse frequency', using it as a sure sign, that he constructed a clepsydra containing a precise amount [of water], specified according to the normal pulse at each age; he would arrive at the patient's bedside, set up the clepsydra and feel the pulse of the person with fever; he would declare that the pulse was 'more frequent', that is that the patient had more (or less) fever, in accordance with the amount by which the motions of the pulse exceeded the normal number, in relation to the filling of the clepsydra. ${ }^{60}$

Although there are other possibilities, it seems most likely that the type of waterclock attributed to Herophilus here at the patient's bedside is one involving inflow to a marked vessel, the various markings corresponding to the time taken for a certain number of pulse beats to be completed by a 'normal' patient, of various ages.

So, what is the significance of what Herophilus (according to Marcellinus) is doing here? One obvious answer is that he is showing off - presenting himself at the patient's bedside with a tool which asserts his superior knowledge and accuracy in relation to that of his rivals, and thus commands confidence.

In more technical, or internal terms, what he is doing is measuring the $p u$ knotēs of the pulse. We have already considered in some detail Galen's treatment of this concept, and the difficulty of equating it straightforwardly with 'pulse rate'. Before proceeding we should pause to consider whether Herophilus' conception is the same as Galen's, or whether there may be a significant difference. Marcellinus, the author who gives us this piece of evidence, in fact also gives us, a little earlier in the same text, an explicit definition of puknotēs and of the distinction between it and speed (tachutēs). ${ }^{61}$ The account he gives seems to be a

58 For the problem of translation of this term see above, pp. 137-8, with n. 29; in spite of the reservation made there, I use 'frequency' in this present context in the interest of readability. 59 Berrey translates: 'frequency becomes primary'; it seems to me rather that the word puknotès is here being used to refer to 'increased frequency' (just as, by a similar semantic stretch, commented on by Galen, megethos can mean both 'size' in the abstract sense of 'magnitude' and also 'bigness').

60 Marcellinus, The Pulse 11, 463 Schöne (= no. 182 in von Staden 1989).

61 Marcellinus, The Pulse 6, 460-1 Schöne. Unfortunately, the date of Marcellinus, as well as his relationship to either Herophilus or Galen, is unclear. Clearly, he is writing some time after Her- 
common-sense one. You are said to go to the country quickly if you complete the journey there quickly, whereas you are said to go there puknōs if the interval of days between your journeys is a short one. This seems potentially to bypass the complexity and subtlety we saw above in Galen's account, whereby he was enabled to treat puknotēs as something discernible within one beat. If so - that is, if puknotēs is defined by Herophilus simply as the 'frequency', as the shortness or length of time between one beat and the next - then the way is indeed open for him to measure it, in a way that it is not for Galen - and indeed, in a way recognizable to us as 'pulse rate'.

And indeed, some such measurement, in a form not dissimilar to its modern descendants, seems to be what is attributed to Herophilus in the above text. We note the distinctive features of puknotēs (in that 'common-sense' understanding, as just specified) that make it accessible to this form of measurement. In the problematic case of speed, considered above, we had a distance travelled and a space of time which would elude any ancient measuring technology. Speed, as understood by both Herophilus and Galen, could admit of no such technology-based measurement. Here, by contrast, we have a clearly countable number that of the beats - and a time period which is long enough to be measurable by a standard, though carefully calibrated, water-clock. By focussing on frequency in our terms, 'rate' - rather than speed, then, and thus on two clearly quantifiable figures - number of beats and a longer, and thus measurable, time span one is, at least in this narrow context, replacing the finely trained human apparatus of tactile assessment and observation with an independent standard. One is, in fact, 'measuring the pulse' according to exactly the same principle by which it was later measured - and sometimes still is - in the modern period, with the advent of portable watches.

How much significance or influence such a quantificatory approach had, even within the narrow context of the 'frequency' of the pulse (which, as we have seen, was to ancient practitioners but one amongst many variables), is unanswerable, certainly on the basis of this isolated ancient report. If the report is to be relied upon, then we seem to have yet another instance of the methodological gulf between Herophilus in Galen, in relation to measurement and quantification, Herophilus here claiming to offer precise measurement of a sort which Galen would never suggest - and which, indeed, as we have seen, is in principle impossible, given Galen's definition of puknotēs.

ophilus; and some have taken the fact that he does not mention Galen as indicating that he predates the latter. On the other hand, some of the terminology and language he uses seems quite close to Galen's. 
Whatever the currency of the quantificatory method attributed to Herophilus in this account, however, it was undoubtedly the model of the individual practitioner's highly trained senses and expert skills of analysis that remained by far the dominant one - as, indeed, it had to, in a world where so small a part of the observable phenomena taken to be relevant to medicine could admit of any kind of quantification or precise measurement. (See figure 15.)

It should be mentioned, however, as a coda, that the musical or metrical model of pulse assessment enjoyed great influence in later times, constituting one aspect of ancient pulse theory that was taken up with particular enthusiasm, especially in the Renaissance. ${ }^{62}$

\section{Conclusion}

A number of fundamental conceptual or philosophical points, then, emerge from Galen's and other technical discussions of time in relation to motion, alongside several points of practical or clinical significance.

The conceptual or philosophical points may be summarized as follows:

(1) Our perception of time is - according to Galen, but in contradiction of the Aristotelian tradition - sui generis: neither the abstract conception of time nor our human perception of depends on that of motion.

(2) Our perception of speed - though its precise quantification or measurement is possible in theory, and on the larger scale also in practice - is, again according to Galen, fundamentally qualitative at the 'micro' level, and therefore is so in many clinical contexts.

(3) Although time, like space, is continuous in its structure, it may be usefully divided into minimal or atomic units, especially in the context of the establishment of ratios or rhythms. According to Galen, our perception of the passing of time, as of the motion of objects - and therefore also of speed - takes place on the basis of such minimal units, that is, time is atomic in its structure from the point of view of perception, even though in its true nature it is not. According to other theorists, such minimal or atomic time units may either (a) correspond to universal physiological realities, or (b) represent divisions of the time continuum which are of crucial pragmatic value, although they are not there 'in nature'.

62 See e.g. Siraisi (1975). 


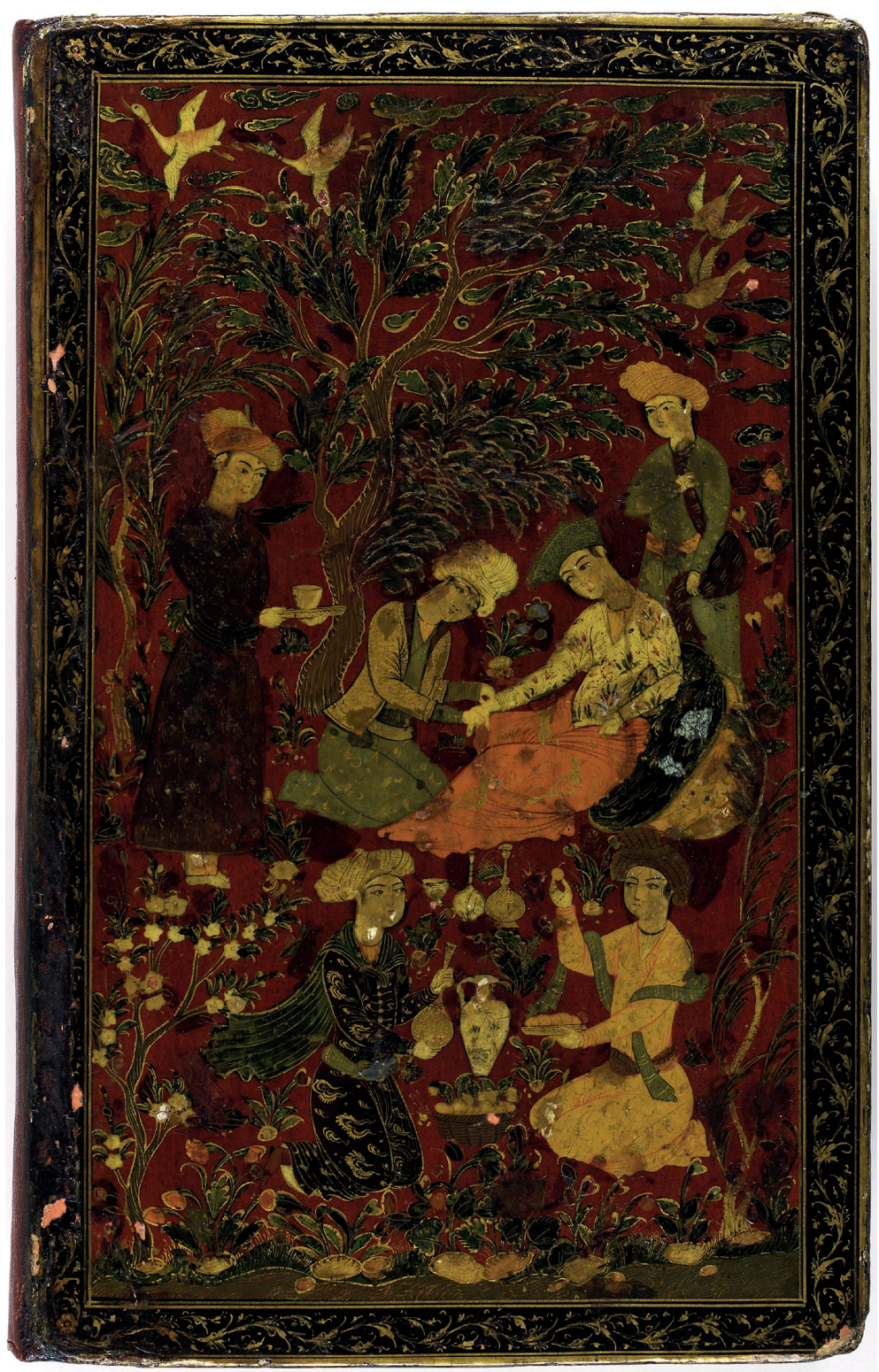

Figure 15: The fine-tuning of the senses (2): the hands and the pulse. A doctor takes a woman's pulse. From a manuscript of Avicenna's Canon, image from Wellcome Collection, London 
More important, though, than these theoretical analyses and considerations, in practical terms - and more important for Galen and Aristoxenus - is the notion that it is possible to develop and fine-tune our senses in a way relevant to clinical (or musical) practice, the notion of a rationally informed training and technical expertise arising in response to the challenges of time, speed and rhythm. Of course, there is little in Galen's theoretical medical model, in his diagnostic judgements or therapeutic recommendations - or in those of his predecessors, such as Herophilus - that we would find persuasive. We will not be concerned to measure or assess the same variables that they claimed to, nor will we find their specific claims for their success in measurement or assessment of them convincing. In Galen's assertion of the notions of fine-tuned sense training, however, and of its complex relationship with verbal reasoning and mental conceptions on the one hand, and radical experiential incommunicability, on the other, as well as in his statement of their potential relevance to the practice of an art, he makes a unique contribution to ancient technical, medical and philosophical thought, and one which presents points of interest and challenge for us today.

Our study has revealed the fundamental significance of time awareness, time assessment and time management in the ancient world, in a variety of experiential and scientific contexts. The particular ways in which this significance manifests itself, in terms of medical and philosophical theories, social and cultural preoccupations, and measuring technologies, are strikingly different in the GraecoRoman world from their instantiation in the globalized twenty-first century. Different, too, in particular, is the balance between the competing claims of quantification and precision and those of educated sense training and subjective judgement. We have, however, seen anxieties, concerns and intellectual ambitions which are in many ways familiar, playing themselves out in a very unfamiliar - and constantly surprising - historical theatre. 